\title{
Leishmania (L.) amazonensis-induced inhibition of nitric oxide synthesis in host macrophages
}

\author{
Filomena M. Perrella Balestieri a , Allan R. Pires Queiroz ${ }^{\text {b }}$, Cristoforo Scavone ${ }^{\text {c }}$, \\ Vlaudia M. Assis Costa ${ }^{\mathrm{d}}$, Manoel Barral-Netto ${ }^{\mathrm{b}}$, Ises de Almeida Abrahamsohn ${ }^{\mathrm{d}, *}$ \\ ${ }^{a}$ Departamento de Fisiologia e Patologia/Laboratório de Tecnologia Farmacêutica, UFPB, João Pessoa, CEP 58051-970, PB, Brazil \\ ${ }^{\mathrm{b}}$ Centro de Pesquisas Gonçalo Muniz, FIOCRUZ e Faculdade de Medicina UFBA, CEP 40295-001, Salvador-BA, Brazil \\ ${ }^{\mathrm{c}}$ Departamento de Farmacologia, ICB/USP, Avenida Prof. Lineu Prestes 1730, Cidade Universitária, \\ CEP 05508-900, São Paulo, SP, Brazil \\ ${ }^{\mathrm{d}}$ Departamento de Imunologia, ICB/USP, Avenida Prof. Lineu Prestes 1730, Cidade Universitária, CEP 05508-900, São Paulo, SP, Brazil
}

Received 4 April 2001; accepted 14 August 2001

\begin{abstract}
Inhibition of lipopolysaccharide (LPS)-induced nitric oxide (NO) production was demonstrated in J774-G8 macrophages infected with Leishmania (L.) amazonensis promastigotes. The downmodulation of NO production observed in infected and LPS-stimulated J774-G8 cells correlated with a reduction in inducible nitric oxide synthase (iNOS) activity. Reduction in iNOS activity was not paralleled by decreased iNOS mRNA expression, suggesting that the parasite affects post-transcriptional events of NO synthesis. Supplementation with L-arginine or tetrahydrobiopterin did not increase NO production, suggesting that inhibition is not due to an insufficiency of substrate or co-factor. Treatment with anti-IL-10, anti-IL-4 or anti-TGF- $\beta$ neutralizing antibodies also failed to increase NO production, indicating that these cytokines are not involved in the observed parasite-induced inhibition of NO synthesis. However, treatment of the cultures with IFN- $\gamma$ resulted in a marked increase in NO production by infected LPS-stimulated cells. These results show that although $L$.(L.) amazonensis infection inhibits iNOS activity and NO production by J774-G8 cells, activation by IFN- $\gamma$ is capable of overriding the suppression of NO synthesis. (c) 2002 Éditions scientifiques et médicales Elsevier SAS. All rights reserved.
\end{abstract}

Keywords: Leishmania (L.) amazonensis; Macrophage; Nitric oxide; INOS activity; INOS mRNA; IFN- $\gamma$

\section{Introduction}

Leishmaniasis is caused by different Leishmania species, which invade and multiply within macrophages of the skin, mucous membranes and viscera 1,2$]$

Both in vitro and in vivo experimental models have demonstrated that leishmanicidal activity in murine macrophages is mediated by reactive nitrogen intermediates especially nitric oxide (NO) [3,4]. In macrophages, NO production is catalyzed by the enzyme inducible nitric oxide synthase (iNOS) which is produced upon in vitro activation by IFN- $\gamma$ or TNF- $\alpha$ in the presence of LPS or by a combination of both cytokines. Various inducible and constitutive co-factors are required for full iNOS activity. These

\footnotetext{
* Corresponding author. Tel./Fax: +55-11-3818-7383.

E-mail address: iabraham@usp.br (I.d.A. Abrahamsohn).
}

include the electron donor NADPH, FAD, FMN and tetrahydrobiopterin $(\mathrm{Tb} 4)$ [5,6].

The importance of NO in leishmanicidal activity exerted by macrophages has been demonstrated by the increase in parasite load upon its inhibition with NO antagonists [7.8. Additionally, Leishmania (L.) major infection leads to progressive disease in mouse strains in which the gene coding for iNOS has been disrupted [9].

In spite of the potent leishmanicidal mechanisms of macrophages, Leishmania can infect and multiply in these cells. Several mechanisms may explain the resistance of Leishmania to the macrophage defense response [10-12] One important factor for parasite survival is that infected cells are less responsive to cytokine activation [13,14] Furthermore, bone marrow-derived macrophages infected in vitro with $L$.(L.) major did not produce cytokines such as TNF- $\alpha$ [15], which could lead to suboptimal NO produc 
tion. Additionally, peritoneal macrophages infected in vitro with L.(L.) amazonensis [10] or L.(L.) braziliensis [16] produce TGF- $\beta$, an inhibitor of NO synthesis.

It has been shown that the parasite itself has mechanisms which may interfere with NO production and thus facilitate survival inside the macrophages. Parasite molecules such as GIPLs and LPG from L.(L.) major [17,18] can inhibit LPS-induced NO synthesis by macrophage cell lines. However, little is known of the mechanisms underlying this inhibition or how it is modulated.

In order to further explore the mechanisms by which Leishmania parasites may affect NO synthesis, we investigated in the present report the effect of $L$.(L.) amazonensis infection on LPS-stimulated NO production by the murine macrophage cell line J774-G8.

\section{Materials and methods}

\subsection{Parasites}

Promastigotes of L.(L.) amazonensis (strain MHOM/BR88 /BA-125-Leila) were maintained at $28-30{ }^{\circ} \mathrm{C}$ in Schneider's Drosophila medium (Sigma Chemical Co., St. Louis, MO) supplemented with $10 \%$ heat-inactivated fetal calf serum (FCS). Parasites were cultured for 5-7 days and stationary-phase promastigotes were harvested and washed with RPMI-1640 tissue culture medium (Sigma Chemical Co.).

\subsection{J774-G8 cells culture}

The murine macrophage cell line J774-G8 (ATCC, Rockville, MD) was cultured in RPMI-1640 supplemented with $2 \mathrm{mM}$ L-glutamine, 100 units $/ \mathrm{ml}$ penicillin, $100 \mu \mathrm{g} / \mathrm{ml}$ streptomycin and 10\% heat-inactivated FCS (Sigma Chemical Co.). The macrophage suspension was cultured in triplicate, either plated out in 24-well plates $\left(2 \times 10^{6}\right.$ cells/well) or in polypropylene tubes, and incubated with lipopolysaccharide (LPS) from Escherichia coli serotype 0111:B4 (1 $\mu \mathrm{g} / \mathrm{ml})$ (Sigma Chemical Co.), Leishmania (ten, five or two parasites per cell) or with a combination of LPS and Leishmania. In the latter situation, the cultures were infected for $4 \mathrm{~h}$ at $30{ }^{\circ} \mathrm{C}$ before adding LPS. The cells were then cultured for $48 \mathrm{~h}$ at $37^{\circ} \mathrm{C}$ at $5 \% \mathrm{CO}_{2}$ and the supernatants were harvested for measurement of nitrite. Treatment with L-arginine or with $\mathrm{Tb} 4$ (both purchased from Sigma Chemical Co.) was started simultaneously with LPS.

\subsection{Determination of nitrite concentration}

Nitrite $\left(\mathrm{NO}_{2}^{-}\right)$accumulation in supernatants of cultured cells was used as an indicator of NO production and was determined by the Griess reaction (detection limit: $1.56 \mu \mathrm{M}$ ) with sodium nitrite as a standard as previously described
[19]. Fifty microliters of supernatants were incubated with $50 \mu \mathrm{l}$ of the solution containing $\mathrm{N}$-[naphthyl]ethylenediamine dihydrochloride (Need) $(1 \mathrm{mg} / \mathrm{ml})$, sulfanilamide $(10 \mathrm{mg} / \mathrm{ml}), 5 \%$ phosphoric acid and distilled water for $10 \mathrm{~min}$. The absorbance at $540 \mathrm{~nm}$ was then measured.

\subsection{Assay for NO synthase activity}

The macrophages were dispensed into polypropylene tubes at $3 \times 10^{6}$ cells $/ \mathrm{ml}$ and infected with $L$. $(L)$ amazonensis stationary-phase promastigotes (ten parasites per cell) for $4 \mathrm{~h}$. The extracellular parasites were removed by three washing cycles with RPMI medium. The cultures were further stimulated with LPS $(1 \mu \mathrm{g} / \mathrm{ml})$ and incubated at $37^{\circ} \mathrm{C}$. Control cultures included cells incubated only in medium, LPS or only infected with Leishmania (ten parasites per cell) for $4 \mathrm{~h}$ at $30^{\circ} \mathrm{C}$. After $20 \mathrm{~h}$, the cells were centrifuged, washed twice (6400 rpm, $5 \mathrm{~min}$ ) in extraction buffer (HEPES $20 \mathrm{mM}$; sucrose $0.32 \mathrm{M}$; dithiothreitol 1.0 $\mathrm{mM}$; leupeptin $10 \mu \mathrm{g} / \mathrm{ml}$; aprotinin $2 \mu \mathrm{g} / \mathrm{ml}$; pepstatin 1.0 $\mathrm{mM}$ and PMFS $1.0 \mathrm{mM}$ ) and then assayed for NO synthase activity by formation of $\left[{ }^{3} \mathrm{H}\right]$ citrulline as previously described [20]. Briefly, after centrifugation, the cell pellets $\left(3 \times 10^{6}\right.$ cells $)$ were lysed by sonication and incubated for 10 min with $\mathrm{H}^{+}$Dowex $50 \times 8-200$ resin converted to sodic form $\left(\mathrm{Na}^{+}\right)$. Samples were then incubated for $60 \mathrm{~min}$ with the co-factors: $2 \mathrm{mM}$ of the reduced form of nicotinamide dinucleotide phosphate (NADPH), $4 \mu \mathrm{M}$ flavine adenine dinucleotide (FAD), $4 \mu \mathrm{M}$ flavine mononucleotide (FMN), $4 \mu \mathrm{M} \mathrm{Tb} 4$ and with $1.0 \mu \mathrm{Ci} / \mu \mathrm{l}$ of the labeled substrate (L-arginine $\left(\mathrm{L}-\left[2,3,4,5-{ }^{3} \mathrm{H}\right]\right.$ arginine monohydrochloride - specific activity: $63.0 \mathrm{Ci} / \mathrm{mmol}$ — bought from Amersham Lab., Buckinghamshire, England. Total volume of the assay was $200 \mu$ l. The reaction was stopped with stop buffer solution (20 mM L-arginine plus $50 \mathrm{mM}$ EDTA). The samples were run through sodic form-Dowex $50 \times 8-200$ resin columns and the eluates collected. Eluates were homogenized with scintillation fluid and counted in a scintillation counter. Vials containing distilled water, scintillation fluid and ${ }^{3} \mathrm{H}$-L-arginine were used as controls. Enzyme activity was expressed as mmol $\left[{ }^{3} \mathrm{H}\right]$ citrulline formed per minute per milligram of protein in the cell extract. Protein concentration was determined by the Bradford method (Bio-Rad Labs, CA, USA).

\subsection{Analysis of iNOS $m R N A$ expression by competitive RT-PCR}

HPRT and iNOS transcripts were evaluated by a semiquantitative PCR using a competitive plasmid (pLOC) 21], kindly provided by Dr Ken Gollob (UFMG, MG, Brazil), who amplified and purified this plasmid which contains the sequence of iNOS and several cytokines and was originally donated by Dr R. Locksley (University of California, San 
Francisco, USA). J774 cells $\left(2 \times 10^{6} / \mathrm{ml}\right)$ were cultured in polypropylene tubes with LPS $(1 \mu \mathrm{g} / \mathrm{ml})$ or Leishmania $(10$ parasites/cell) plus LPS as described above for different periods of time. Cells were collected $\left(10^{7}\right)$, washed and stored at $-70{ }^{\circ} \mathrm{C}$. RNA extraction was performed using Trizol (GIBCO BRL, Rockville, MD, USA); chloroform, isopropanol and ethanol were added to the RNA pellet. After centrifugation, ethanol was removed and $30 \mu \mathrm{l}$ of $0.01 \%$ diethil pyrocarbonate (DEPC) distilled water were added.

cDNAs were obtained by reverse-transcription (RT) and amplified by the polymerase chain reaction (PCR). RNA (1-6 $\mu \mathrm{g})$ from each sample was incubated with $1.5 \mu \mathrm{l}$ of oligo dT12-18 at $70{ }^{\circ} \mathrm{C}$, for $10 \mathrm{~min}$. After rapid cooling in ice, $10 \mu \mathrm{l}$ of mix solution ( $6 \mu \mathrm{l}$ of $5 \times$ synthesis buffer; $1.5 \mu \mathrm{l}$ of $10 \mathrm{mM}$ dNTP; $3 \mu \mathrm{l}$ of $0.1 \mathrm{M}$ DTT and $1 \mu \mathrm{l}$ of superscript $\mathrm{R} / \mathrm{T}$ II $(200 \mathrm{U} / \mu \mathrm{l})$ were slowly added to the samples. After incubation (10 $\mathrm{min}$, room temperature), the samples were sequentially incubated for $50 \mathrm{~min}$ at $40{ }^{\circ} \mathrm{C}, 5 \mathrm{~min}$ at $90{ }^{\circ} \mathrm{C}$ and $5 \mathrm{~min}$ at $4{ }^{\circ} \mathrm{C}$. Samples were then rapidly centrifuged and incubated $\left(20 \mathrm{~min}, 37^{\circ} \mathrm{C}\right)$ with $1 \mu \mathrm{l}$ of RNAse $\mathrm{H}$.

cDNA samples were amplified with purified competitor plasmid (pLOC) containing the iNOS sequences between 0.2 and $0.012 \mathrm{pg}$ per reaction. The cDNA contents of the samples were equalized by determining the HPRT concentration and adjusting their concentration. After this adjustment, $5 \mu \mathrm{l}$ of each sample were mixed with $10 \mu \mathrm{l}$ of serially diluted competitor sequences $(8,2$ and $0.5 \mathrm{pg} / \mathrm{ml})$ and used in the PCR reaction. During this reaction, $\mathrm{pLOC}$ and cDNA compete for the specific iNOS primer and both are coamplified, resulting in 390-bp fragments (derived from pLOC amplification) and 306-bp fragments (derived from cDNA amplification). The HPRT primer amplified a 450-bp fragment for competitor and a 352-bp fragment for sample cDNA. PCR products originated from plasmid and sample cDNA were separated by electrophoresis in $1.5 \%$ agarose gel stained with ethydium bromide. The relative intensity of the band originating from the sample cDNA band versus that from the competitor cDNA was then compared between different samples. The amplification with the HPRT primer was used to confirm the equalization of cDNA content. The primer sequences used were as follows: 1) for HPRT, (5' GTTGGATACAGGCCAGACTTTGTTG 3' and 5'GAGGGTAGGCTGGCCTATGGCT 3'); 2) for iNOS, (5'TGGAATGGAGACTGTCCCAG3' and 5'GGGATCTGAATGTGATGTTTG 3').

PCR conditions were as follows: sample cDNA $(10 \mu \mathrm{l})$ was amplified by 35 cycles (Thermocycler MJ Research Co., NJ, USA) in a solution containing $5 \mu \mathrm{l}$ of PCR $10 \times$ buffer $(100 \mathrm{mM}$ Tris, $\mathrm{pH} 9.0 ; 500 \mathrm{mM} \mathrm{KCl} ; 1 \%$ Triton X-100 and $15 \mathrm{mM} \mathrm{MgCl}_{2}$ ), $1 \mu \mathrm{l}$ of $10 \mathrm{mM} \mathrm{dNTP}, 1 \mu \mathrm{l}$ of 5 OD sense and anti-sense primers, $0.25 \mu \mathrm{Taq}$ polymerase (0.25 U/reaction) and $12 \mu \mathrm{l}$ of water. The PCR cycling conditions were: initial denaturation of $2 \min \left(94^{\circ} \mathrm{C}\right), 35$ cycles at $92{ }^{\circ} \mathrm{C}$ for $40 \mathrm{~s}$, at $65^{\circ} \mathrm{C}$ for $20 \mathrm{~s}$ and at $72{ }^{\circ} \mathrm{C}$ for $40 \mathrm{~s}$, followed by a final extension at $72{ }^{\circ} \mathrm{C}$ for $10 \mathrm{~min}$.

\subsection{Cytokine assays and cytokine and anti-cytokine treatment}

TNF- $\alpha$, IL-12 (p40), IL-10 and IL-4 were quantified by sandwich ELISA assays using pairs of antibodies and standards purchased from Pharmingen, San Diego, CA, USA. TGF- $\beta$ was quantified by a biological assay using CCL64 cells as targets [22]. Treatment of the cultures with mouse rIFN- $\gamma$ (R \& D Systems, Minneapolis, MN, USA) was carried out by adding this cytokine together with the LPS stimulus. In some experiments, the cultures were treated with neutralizing Abs to IL-10 (2 A 5), IL-4 (11 B 11) or TGF- $\beta$ (1D11-16); all were used at $20 \mu \mathrm{g} / \mathrm{ml}$, a dose that was found to be highly effective at neutralizing cytokine production in culture [23]

\subsection{Data analysis}

Results are expressed as the arithmetic mean of triplicates accompanied by the respective standard deviation. Means of control and experimental groups were compared by Student's $t$ - test. Comparisons of multiple groups were performed by ANOVA and Bonferroni's test. Differences were considered to be significant when $P<0.05$. Statistical analysis was performed using Graph Pad Instat, version $2.04 \mathrm{a}$.

\section{Results}

\subsection{Infection of macrophages with L.(L.) amazonensis suppresses iNOS activity and NO synthesis by in vitro cultured macrophages}

Activation of J774-G8 cells by LPS led to increased production of nitrite in the culture medium (Eig_-1 $)$. However, when the cells had been infected with Leishmania promastigotes at a ratio of 10 parasites/cell for $4 \mathrm{~h}$ prior to LPS activation, a marked reduction in nitrite production was observed in culture supernatants. Reduction in nitrite production was also observed at lower parasite/cell ratios. (Eig 1). Exposure of J774-G8 cells only to Leishmania promastigotes resulted in nitrite production levels similar to those obtained in unstimulated cells.

We further looked at the expression of iNOS enzymatic activity by infected and non-infected J774-G8 cells in relation to nitrite production levels. These cells, when cultured for $20 \mathrm{~h}$ without stimulation, expressed iNOS activity, but the corresponding nitrite concentrations in the supernatants were quite low $(4.8 \mu \mathrm{M})$ (Eig_ 2A vs. 2B). LPS-stimulated cultures showed a $48 \%$ increase in iNOS activity (Eig. 2A ) accompanied by a three-fold increase in nitrite levels (Eig_ 2B ) when compared to unstimulated cells. Cells that were infected with Leishmania prior to LPS stimulation showed a marked reduction in iNOS activity (Eig_2A), which was also reflected in a marked decrease in 


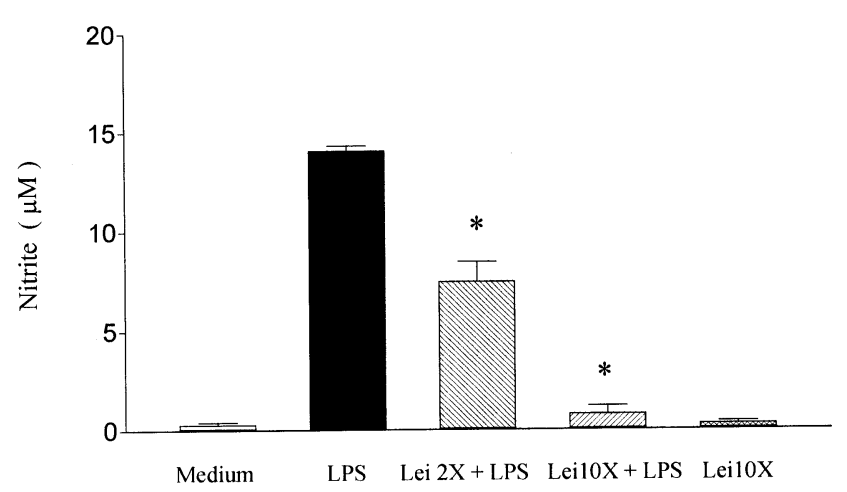

Fig. 1. LPS-stimulated NO production by J774-G8 cells infected by $L$. $(L$.) amazonensis. J774-G8 cells were cultured for $4 \mathrm{~h}$ with different ratios of L.(L.) amazonensis promastigotes per cell. Control cells were not infected with parasites. After this time, the cells were washed and incubated with medium or LPS $(1 \mu \mathrm{g} / \mathrm{ml})$. Forty-eight hours later, the supernatants were collected and nitrite concentrations were evaluated by Griess reaction. * $P<0.05$ LPS-stimulated infected vs. identically stimulated uninfected cultures. Representative of three experiments.

nitrite production in the cultures as compared to LPSstimulated cells. Infection of the cultures with Leishmania resulted in approximately $70 \%$ reduction in enzyme activity (Fig 2A) compared to unstimulated cultures with similar nitrite production levels (Fig 2B). Absence of NADPH in the quantification assay abrogated enzyme activity, confirming that detected activity was due to iNOS (data not shown). Taken together, these results indicate that Leishmania infection interferes with iNOS enzyme activity in J774-G8 cells and prevents the LPS-induced increases in enzymatic activity and corresponding NO synthesis.

\subsection{Leishmania-mediated suppression of iNOS activity and NO synthesis is not accompanied by a reduction in iNOS mRNA expression levels and is not reversed by supplementation with L-arginine or with Tb4}

Reduction in iNOS activity may occur by inhibition of iNOS mRNA expression or by other mechanisms mediated by co-factor and substrate availability. Expression of iNOS mRNA was analyzed by semi-quantitative competitive RTPCR. Leishmania infection of J774-G8 cells did not decrease the expression of iNOS mRNA $6 \mathrm{~h}$ after LPS stimulation, as iNOS mRNA was expressed at similar concentrations in LPS-stimulated cells as in infected and LPS-stimulated ones (Eig_ 3). NO production by murine macrophages is dependent on the availability of L-arginine and $\mathrm{Tb} 4$ which act as substrate and co-factors for iNOS. One possibility to explain the reduced iNOS activity and NO production in Leishmania-infected cells that, however, was not accompanied by reduced mRNA levels, could be insufficient amounts of those co-factors. Supplementing the cultures with L-arginine (up to $4 \mathrm{mM}$ concentrations) or

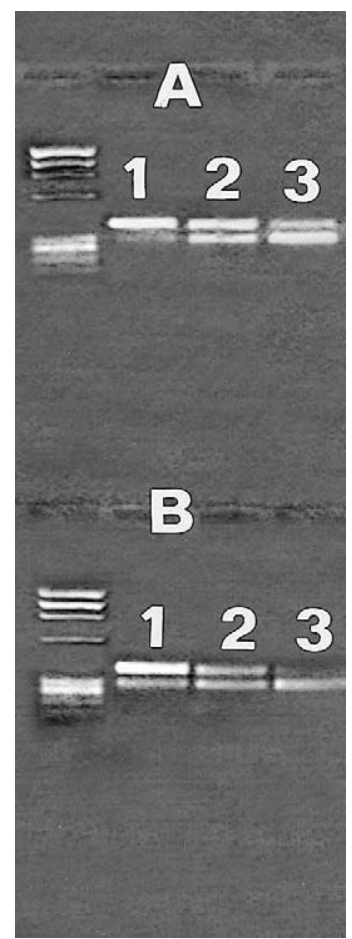

Fig. 3. iNOS mRNA expression by quantitative RT-PCR in LPS-stimulated J774-G8 cells infected or not with $L .(L$.) amazonensis. J774-G8 cells $\left(1 \times 10^{7} / \mathrm{ml}\right)$ were infected with $L .(L$.$) amazonensis and stimulated with$ LPS ( $1 \mu \mathrm{g} / \mathrm{ml})$ (B). Control cells were stimulated only with LPS (A). Six hours after LPS activation, the cultured cells were analyzed for iNOS mRNA expression by RT-PCR. iNOS mRNA was amplified by RT-PCR in the presence of the competitor plasmid. The iNOS primer amplified a 390-bp fragment for the competitor (superior bands) and a 306-bp fragment for the sample cDNA (inferior bands) [ $8 \mathrm{pg} / \mathrm{ml}$ (1), $2 \mathrm{pg} / \mathrm{ml}$ (2) and 0.5 $\mathrm{pg} / \mathrm{ml}$ (3) of competitor plasmid]. Note that the sample cDNA is amplified similarly in $\mathrm{A}$ and $\mathrm{B}$ in relation to the amplification of the competitor plasmid; equivalence is reached for iNOS mRNA in both $\mathrm{A}$ and $\mathrm{B}$ at 2 $\mathrm{pg} / \mathrm{ml}$ of the competitor plasmid.
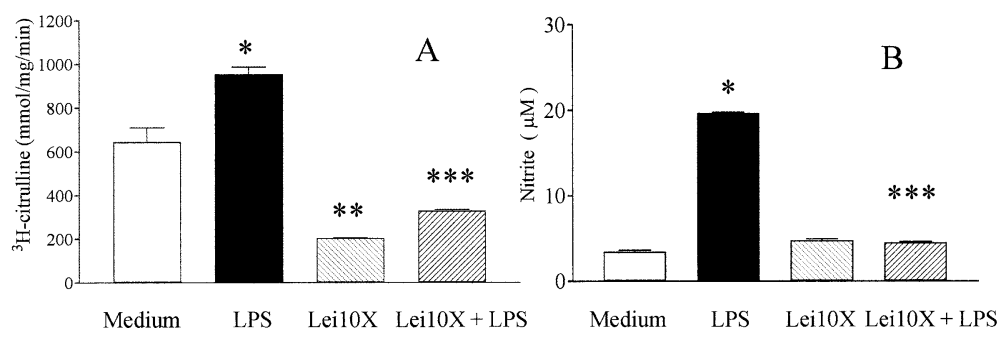

Fig. 2. iNOS activity and NO production by LPS-stimulated J774-G8 cells infected with $L$.(L.) amazonensis. J774 cells were infected for $4 \mathrm{~h}$ with $L$.(L.) amazonensis (ten parasites/cell), washed and stimulated with LPS $(1 \mu \mathrm{g} / \mathrm{ml})$. Control cells were cultured with or without LPS. Twenty hours after LPS activation, iNOS activity was quantified (A) and nitrite concentrations were measured in the supernatants (B). $* P<0.05$ LPS-stimulated vs. unstimulated cultures; $* * P<0.05$ unstimulated infected vs. uninfected cultures; *** LPS-stimulated infected vs. uninfected cultures. Representative of two experiments. 


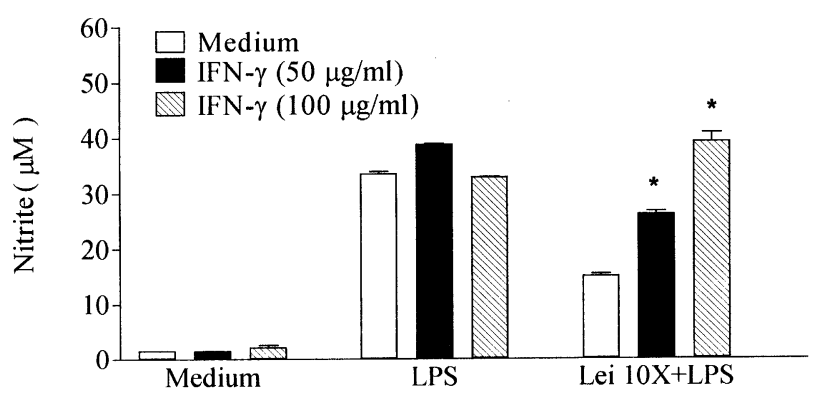

Fig. 4. Effect of IFN- $\gamma$ treatment on LPS-stimulated NO production by J774-G8 cells infected with $L$.(L.) amazonensis. J774-G8 cells infected for $4 \mathrm{~h}$ with $L .(L$.) amazonensis (ten parasites/cell) were washed, LPS activated and treated or not with rIFN- $\gamma(50$ and $100 \mathrm{U} / \mathrm{ml})$. UninfectedLPS activated cultures were also treated with rIFN- $\gamma$. Forty-eight hours later, supernatants were collected and nitrite concentrations were measured. $* P<0.05$ infected and rIFN- $\gamma$-treated LPS-activated vs. similarly infected and LPS-activated cultures that were not treated with the cytokine. Representative of three experiments.

with $\mathrm{Tb} 4$ (up to $100 \mu \mathrm{M}$ concentrations) did not result in increased NO production by LPS-activated and infected J774-G8 cells (data not shown). Similar results were also observed in cultures from infected and LPS-stimulated resident peritoneal cavity cells (results not shown) suggesting that inhibition of NO synthesis by L.(L.) amazonensis promastigotes is not due to insufficient L-arginine and/or Tb4 availability in the culture medium.

\subsection{Leishmania-mediated suppression of NO synthesis can be modulated by cytokines}

As IFN- $\gamma$ plays a major role in iNOS activation, we investigated whether treatment with recombinant IFN- $\gamma$ could increase NO production by J774-G8 cells infected with Leishmania. Addition of rIFN- $\gamma$ to the cultures at 50 or $100 \mathrm{U} / \mathrm{ml}$ moderately increased NO production by LPSstimulated cells and practically restored NO production levels in the cultures that were infected with the parasites prior to LPS stimulation ( $\operatorname{Fig}_{4}$ ). The increase in NO synthesis stimulated by rIFN- $\gamma$ was not due to suppression of TGF- $\beta$ or IL-10 production (data not shown).

In the course of these experiments, IL-12 production levels were also measured in LPS-stimulated and in Leishmania-infected LPS-stimulated cultures. It was found that while the former produced IL-12 (p40) in the order of $644 \mathrm{pg} / \mathrm{ml}$, in the latter condition this cytokine was below detection levels, suggesting that suppression of NO synthesis by parasitism is paralleled by a suppression of the IL-12 response to LPS stimulation. Addition of rIL-12 either alone or in combination with IFN- $\gamma$ did not further enhance NO production (data not shown). In contrast to IL-12, synthesis of TNF- $\gamma$ to LPS stimulation was not inhibited by previous infection of the cells with Leishmania (data not shown).

\section{Discussion}

Survival of Leishmania inside monocytes and macrophages depends on their ability to evade cytotoxic mechanisms exhibited by these cells. We found that infection of unprimed J774-G8 murine macrophages with $L$.(L.) amazonensis led to inhibition of iNOS activity and NO production when the cells were further stimulated with LPS. As NO constitutes a major effector molecule in the destruction of intracellular Leishmania by murine macrophages, our findings suggest that interference with the ability to synthesize NO may constitute an important evasion mechanism for the parasite.

Inhibition of NO production by macrophages is not restricted to Leishmania infection, as it has been described as a potential evasion mechanism by other intracellular pathogens. Trypanosoma cruzi trypomastigotes cultured with cytokine-activated resident peritoneal macrophages leads to decreased NO production [24]. Infection of activated alveolar macrophages by Mycobacterium bovis BCG [25] or of peritoneal macrophages with Cryptococcus neoformans [26] also results in suppressed NO production.

Little is known about the mechanisms that underlie the inhibition of NO synthesis by the pathogens or their products. Infection with live parasites is not an absolute requirement because parasite molecules such as GIPLs or LPG extracted from L. major were also found to inhibit NO synthesis 17.18] Our own observations indicate that heatkilled L. amazonensis, but not an antigenic extract of these parasites, is also capable of inhibiting NO production (unpublished observations). An LPG-associated molecule of L.(L.) donovani, kinetoplastid membrane protein-11, has been described to contain at position 45, a structural analogue of $\mathrm{N}^{\mathrm{G}}$-monomethyl-L-arginine, a well-known inhibitor of NO synthesis that acts by competing with L-arginine [27]. This could be a mechanism by which NO production by macrophages is downregulated in this species of Leishmania. However, a similar mechanism is unlikely to be occurring in our model, as supplementation with L-arginine failed to increase NO production levels.

Our results show that NO downmodulation in LPSstimulated and infected cells is caused by inhibition of the enzyme (iNOS) activity and that there is no reduction in iNOS mRNA expression at $6 \mathrm{~h}$ after LPS stimulation in Leishmania-infected cultures compared with uninfected cultures. When tested later $(18 \mathrm{~h})$, iNOS mRNA was partially degraded and precluded quantification analysis. Indeed, it has been shown that iNOS mRNA is only transiently elevated after LPS or cytokine stimulation reaching a maximum 3-6 $\mathrm{h}$ after stimulation and then suffers a quick breakdown, returning to baseline levels over the next $20 \mathrm{~h}$; degradation of the message could be inhibited by protein synthesis inhibitors [28].

Transcription of the iNOS gene occurs following LPS activation of TNF- $\alpha$ and IFN- $\beta$ genes in macrophages [29] In addition, we did not observe a decrease in TNF- $\alpha$ 
production in infected and LPS-stimulated J774-G8 cells. Results from infected and LPS-activated peritoneal cells also indicate that there is no reduction in IFN type I production levels in spite of inhibition of NO synthesis (unpublished results) .

Taken together our results suggest that infection by $L .(L$.) amazonensis may interfere with post-transcriptional events during cellular activation by LPS. Induction of iNOS mRNA is post-transcriptionally downregulated by IL-4, IL-10 and TGF- $\beta$ [3,30.31]. Negative effects on NO synthesis by these cytokines were discarded because specific monoclonal antibodies reactive against these molecules did not upregulate NO levels and there were no significant differences in the levels of these cytokines between LPSactivated cells and LPS-activated and infected cells (data not shown).

Besides cytokines that modulate transcription and stability of iNOS mRNA, the activity of iNOS and the rates of NO synthesis are regulated by co-factors such as L-arginine and Tb4. L-arginine is the substrate for catalytic activity of iNOS for NO synthesis and this amino acid and $\mathrm{Tb} 4$ are important for homodimerization of iNOS and rate-limiting of its activity [32.33]. As oxidation by catalase or loss of Tb4 activity are reported to be causes of decreased iNOS activity [33.34], we supplemented the medium of infected LPS-stimulated cells with Tb4. However, there was no increase in NO production, suggesting that reduction in NO synthesis cannot be ascribed to Tb4 limitation. Regarding L-arginine availability, arginase production by LPSactivated macrophages [35] and/or by Leishmania [36] could putatively degrade L-arginine. Yet, supplementation of the culture medium with this amino acid also failed to restore NO production by Leishmania-infected cells. Nevertheless, inhibition of NO production by $L .(L$.$) enriettii-$ infected macrophages was reverted by L-arginine addition ( $4 \mathrm{mM})$ to the culture medium [37. Our results suggest that iNOS enzyme activity inhibition in $L .(L$.) amazonensisinfected and LPS-stimulated cells is not caused by low concentrations of these molecules, particularly because in enzymatic activity assays all co-factors and substrate are available. However, it cannot be ruled out that Leishmania infection may cause modifications in the intracellular transport of L-arginine that would impair its access to the organelles that synthesize NO [3]. Alternatively, Leishmania molecules could interfere with iNOS dimerization, with consequent reduction in co-factor association. Detailed studies have demonstrated that only dimeric, active iNOS displays sites for $\mathrm{Tb} 4$ association [5]

Suppressed NO synthesis by infected and LPS-stimulated J774-G8 cells could be overcome by stimulation of the cultures with rIFN- $\gamma$. This cytokine is produced by activated $\mathrm{T}$ or NK cells, and together with LPS or with TNF- $\alpha$, is a major macrophage activator and inducer of iNOS transcription [3]. The results suggest that activation by rIFN- $\gamma$ together with LPS is capable of overriding whichever mechanisms Leishmania uses to suppress NO in macroph- ages. Effective activation of macrophages to NO production and parasiticidal effect depends on the balance of macrophage-activating and -deactivating cytokines produced by the immune response. Thus, suppression of NO synthesis may provide an initial escape mechanism enabling L. amazonensis to infect the macrophage, but the ultimate fate of the parasites will depend on the cytokines produced during the innate and acquired immune responses.

\section{Acknowledgements}

We thank Mr Ademir V. da Silva and Mr Mauro Sucupira for expert technical assistance. This work was supported by FAPESP and CNPq. F.M.P. Balestieri and V.M.A. Costa were supported by fellowships from PIDCT/CAPES.

\section{References}

[1] F.Y. Liew, C.A. O'Donnell, Immunology of leishmaniasis, Adv. Parasitol. 32 (1993) 161-258.

[2] E. Handman, Cell biology of Leishmania, Adv. Parasitol. 44 (2000) $1-39$.

[3] P.G. Jorens, K.E. Matthys, H. Bult, Modulation of nitric oxide synthase activity in macrophages, Med. Inflammation 4 (1995) $75-89$.

[4] W. Solbach, T. Laskay, The host response to Leishmania major, Adv. Immunol. 74 (2000) 275-317.

[5] J.M. Fukuto, G. Chaudhuri, Inhibition of constitutive and inducible nitric oxide synthase: potencial selective inhibition, Annu. Rev. Pharmacol. Toxicol. 35 (1995) 165-194.

[6] D.J. Stuehr, Structure-function aspects in the nitric oxide synthases, Annu. Rev. Pharmacol. Toxicol. 37 (1997) 339-359.

[7] T.G. Evans, L. Thai, D.L. Granger, J.B. Hibbs Jr, Effect of in vivo inhibition of nitric oxide production in murine leishmaniasis, J. Immunol. 151 (1993) 907-915.

[8] S. Stenger, H. Thüring, M. Röllinghoff, P. Manning, C. Bogdan, L- $\mathrm{N}^{6}$-(1-iminoethyl)lysine potently inhibits inducible nitric oxide synthase and is superior to $\mathrm{N}^{\mathrm{G}}$-monomethyl-arginine in vitro and in vivo, Eur. J. Pharmacol. 294 (1995) 703-712.

[9] X.Q. Wei, I.G. Charles, A. Smith, J. Ure, G.J. Feng, F.P. Huang, D. Xu, W. Müller, S. Moncada, F.Y. Liew, Altered immune responses in mice lacking inducible nitric oxide synthase, Nature 375 (1995) $408-411$.

[10] M. Barral-Netto, A. Barral, C.E. Brownell, Y.A.W. Sheiky, L.R. Ellingsworth, D.R. Twardzik, S.G. Reed, Transforming growth factor- $\beta$ in leishmanial infection: a parasite escape mechanism, Science 257 (1992) 545-548.

[11] P.M. Kaye, N.J. Rogers, A.J. Curry, J.C. Scott, Deficient expression of co-stimulatory molecules on Leishmania-infected macrophages, Eur. J. Immunol. 24 (1994) 2850-2854.

[12] N. Weinheber, M. Wolfram, D. Harbecke, T. Aebischer, Phagocytosis of Leishmania mexicana amastigotes by macrophages leads to a sustained suppression of IL-12 production, Eur. J. Immunol. 28 (1998) 2467-2477.

[13] H. Himmelrich, C. Parra-Lopez, F. Tacchini-Cottier, J.A. Louis, P. Launois, The IL-4 rapidly produced in BALB/c mice after infection with Leishmania major down-regulates IL-12 receptor $\beta 2$-chain expression on $\mathrm{CD} 4+\mathrm{T}$ cells resulting in a state of unresponsiveness to IL-12, J. Immunol. 161 (1998) 6156-6163. 
[14] G.J. Feng, H.S. Goodridge, M.M. Harnett, X.Q. Wei, A.V. Nikolaev, A.P. Higson, F.Y. Liew, Extracellular Signal-Related Kinase (ERK) and p38 Mitogen-Activated Protein (MAP) kinases differentially regulate the Lipopolysaccharide-mediated induction of inducible Nitric Oxide Synthase and IL-12 in macrophages: Leishmania phosphoglycans subvert macrophage IL-12 production by targeting ERK MAP Kinase, J. Immunol. 163 (1999) 6403-6412.

[15] L. Carrera, R.T. Gazzinelli, R. Badolato, S. Hieny, W. Müller, R. Kühn, Sacks D.L., Leishmania promastigotes selectively inhibit interleukin 12 induction in bone marrow-derived macrophages from susceptible and resistant mice, J. Exp. Med. 183 (1996) 515-526.

[16] A. Barral, M. Barral-Netto, E.C. Yong, C.E. Brownell, D.R. Twardzik, S.G. Reed, Transforming growth factor $B$ as a virulence mechanism for Leishmania braziliensis, Proc. Natl. Acad. Sci. USA 90 (1993) 3442-3446.

[17] L. Proudfoot, C. O'Donnell, F.Y. Liew, Glycoinositolphospholipids of Leishmania major inhibit nitric oxide synthesis and reduce leishmanicidal activity in murine macrophages, Eur. J. Immunol. 25 (1995) 745-750.

[18] L. Proudfoot, A.V. Nikolaev, G.J. Feng, X.Q. Wei, M.A.J. Ferguson, J.S. Brimacombe, F.Y. Liew, Regulation of the expression of nitric oxide synthase and leishmanicidal activity by glycoconjugates of Leishmania lipophosphoglycan in murine macrophages, Proc. Natl. Acad. Sci. USA. 93 (1996) 10984-10989.

[19] A.H. Ding, C.F. Nathan, D.J. Stuehr, Release of reactive nitrogen intermediates and reactive oxygen intermediates from mouse peritoneal macrophages. Comparison of activating cytokines and evidence for independent production, J. Immunol. 141 (1988) 2407-2412.

[20] D.J. Stuehr, H.J. Cho, N.S. Kwon, M.F. Weise, C.F. Nathan, Purification and characterization of the cytokine-induced macrophage nitric oxide synthase: An FAD- and FMN-containing flavoprotein, Proc. Natl. Acad. Sci. USA 88 (1991) 7773-7777.

[21] S.L. Reiner, S. Zheng, D.B. Corry, R.M. Locksley, Constructing polycompetitor cDNAs for quantitative PCR, J. Immunol. Methods 165 (1993) 37-46.

[22] S.C. Wallick, I.S. Figari, R.E. Morris, A.D. Levinson, M.A. Palladino, Immunoregulatory role of transforming growth factor $\beta$ (TGF- $\beta$ ) in development of killer cells: comparison of active and latent TGF- $\beta_{1}$, J. Exp. Med. 172 (1990) 1777-1884.

[23] I.A. Abrahamsohn, R.L. Coffman, Cytokine and nitric oxide regulation of the immunosuppression in Trypanosoma cruzi infection, J. Immunol. 155 (1995) 3955-3963.

[24] D.R. Pakianathan, Kuhn R.E., Trypanosoma cruzi affects nitric oxide production by murine peritoneal macrophages, J. Parasitol. 80 (1994) 432-437.

[25] R. Hanano, S.H.E. Kaufmann, Nitric oxide and mycobacterial growth inhibition by murine alveolar macrophages: the sequence of rIFN- $\gamma$ stimulation and Mycobacterium bovis BCG infection determines macrophage activation, Immunol. Lett. 45 (1995) 23-27.
[26] K. Kawakami, T. Zhang, M.H. Qureshi, Saito A., Cryptococcus neoformans inhibits nitric oxide production by murine peritoneal macrophages stimulated with interferon- $\gamma$ and lipopolysaccharide, Cell. Immunol. 180 (1997) 47-54.

[27] A. Jardim, V. Funk, R.M. Caprioli, R.W. Olafson, Isolation and characterization of the Leishmania donovani kinetoplastid membrane protein-11, a major immunoreactive membrane glycoprotein, Biochem. J. 305 (1995) 307-313.

[28] A. Evans, A. Carpenter, J. Cohen, Inducible nitric-oxide-synthase mRNA is transiently expressed and destroyed by a cycloheximidesensitive process, Eur. J. Biochem. 219 (1994) 563-569.

[29] M. Fujihara, N. Ito, J.L. Pace, Y. Watanabe, S.W. Russell, T. Suzuki, Role of endogenous Interferon- $\beta$ in lipopolysaccharide-triggered activation of the inducible nitric-oxide synthase gene in a mouse macrophage cell line, J774, J. Biol. Chem. 269 (1994) 12773-12778.

[30] Y. Vodovotz, C. Bogdan, J. Paik, Q.W. Xie, C. Nathan, Mechanisms of suppression of macrophage nitric oxide release by transforming growth factor B, J. Exp. Med. 178 (1993) 605-613.

[31] C. Bogdan, Y. Vodovotz, J. Paik, Q.W. Xie, C. Nathan, Mechanism of suppression of nitric oxide synthase expression by interleukin- 4 in primary mouse macrophages, J. Leukoc. Biol. 55 (1994) 227-233.

[32] D.J. Stuehr, N.S. Kwon, C.F. Nathan, FAD and GSH participate in macrophage synthesis of nitric oxide, Biochem. Biophys. Res. Commun. 168 (1990) 558-565.

[33] J.K. Baek, B.A. Thiel, S. Lucas, D.J. Stuehr, Macrophage nitric oxide synthase subunits. Purification, characterization, and role of prosthetic groups and substrate in regulating their association into a dimeric enzyme, J. Biol. Chem. 268 (1993) 21120-21129.

[34] Y. Li, A. Severn, M.V. Rogers, R.M.J. Palmer, S. Moncada, F.Y. Liew, Catalase inhibits nitric oxide synthesis and the killing of intracellular Leishmania major in murine macrophages, Eur. J. Immunol. 22 (1992) 441-446.

[35] R.G. Bogle, A.R. Baydoun, J.D. Pearson, S. Moncada, G.E. Mann, L-arginine transport is increased in macrophages generating nitric oxide, Biochem. J. 284 (1992) 15-18.

[36] E.R. Da Silva, L.M. Floeter-Winter, Characterization of the active site of arginase from Leishmania (L.) amazonensis based on the enzyme structure defined for Rattus novergicus, Mem. Inst. Oswaldo Cruz 92 (1997) 166.

[37] Y. Buchmüller-Rouiller, S.B. Corradin, J. Mauël, Macrophage activation for intracellular killing as induced by a $\mathrm{Ca}^{2+}$ ionophore. Dependence on L-arginine-derived nitrogen oxidation products, Biochem. J. 284 (1992) 387-392. 